\title{
Wedged-patch venoplasty of the left liver graft portal vein for size matching in pediatric living donor liver transplantation
}

\author{
Sang-Hyun Kang ${ }^{1}$, Jung-Man Namgoong ${ }^{1}$, Shin Hwang ${ }^{1}$, Dong-Hwan Jung ${ }^{1}$, and Kyung-Mo Kim² \\ Departments of ${ }^{1}$ Surgery and ${ }^{2}$ Pediatrics, Asan Medical Center, University of Ulsan College of Medicine, Seoul, Korea \\ Portal vein (PV) size matching between recipient and liver graft is important in preventing anastomotic stenosis in \\ living donor liver transplantation (LDLT). In right liver grafts, the diameter of graft PV is usually $>10 \mathrm{~mm}$. Thus, PV \\ size matching does not become critical in adult recipients. If the recipient PV is very large, funneling fence can be \\ attached to graft PV. However, if the diameter of graft PV is $<8 \mathrm{~mm}$, it can induce anastomotic stenosis. We experi- \\ enced a few cases of PV anastomotic stenosis due to small-sized graft PV in $>5000$ LDLT cases, but graft PV widen- \\ ing was not performed because graft PV is considered as being a no-touch area. In thinking out of the box, we per- \\ formed wedged-patch venoplasty to exceptionally narrow graft PV. A 4 year-old female patient underwent second LDLT \\ due to progressive deterioration of graft function after 3 years. At first LDLT operation for biliary stresia, an iliac vein \\ conduit was interposed for PV reconstruction. At second LDLT operation, the diameter of interposed PV was $10 \mathrm{~mm}$, \\ but the left liver graft PV was only $6 \mathrm{~mm}$-sized. Uniquely, the left PV was waist only at first-order PV. To resolve \\ this PV waist, a longitudinal incision was made to release the waist. A cold-preserved fresh iliac vein patch was inserted \\ to widen the PV orifice. The patch size was adjusted to match the size of the recipient PV. The patient recovered \\ uneventfully. This wedged-patch venoplasty technique can be applied to small-sized graft PV, to cope with PV size \\ mismatching in LDLT. (Ann Hepatobiliary Pancreat Surg 2019;23:183-186)
}

Key Words: Portal vein stenosis; Venoplasty; Pediatric transplantation

\section{INTRODUCTION}

Size matching of the portal vein (PV) between the recipient and liver graft is important in preventing anastomotic stenosis in living donor liver transplantation (LDLT). In LDLT using a right liver graft, the diameter of right liver graft PV is usually $>10 \mathrm{~mm}$, thus PV size matching does not become a critical problem in adult recipients. If the recipient PV is small, unification venoplasty of two PV braches can be applied. ${ }^{1}$ If the recipient PV is very large, a funneling fence can be attached to the graft PV for easy anastomosis. ${ }^{2}$ However, if the diameter of graft $\mathrm{PV}$ is $<8 \mathrm{~mm}$, it can induce anastomotic stenosis even though a growth factor is fully given at the suture material. We have experienced a few cases of PV anastomotic stenosis so far due to small-sized graft PV in >5000 LDLT cases, but graft PV widening was not performed because graft PV is considered as being a no-touch area.

In thinking out of the box, we performed wedged-patch venoplasty to an exceptionally narrow graft PV to cope with PV size mismatching in LDLT. We herein present the case and describe the surgical technique of wedgedpatch venoplasty.

\section{CASE}

A 14 kg-weighing 4 year-old female patient underwent second LDLT due to progressive deterioration of graft function for 3 years (Fig. 1). The first LDLT operation was performed due to biliary stresia at age of 11 months and the donor was her mother. At the second LDLT, the donor was the 35 year-old sister of her mother and a 350 g-weighing whole left liver with middle hepatic vein trunk was harvested. The left liver graft PV was only $6 \mathrm{~mm}$, be-

Received: April 9, 2019; Revised: April 12, 2019; Accepted: April 13, 2019

Corresponding author: Shin Hwang

Department of Surgery, Asan Medical Center, University of Ulsan College of Medicine, 88 Olympic-ro 43-gil, Songpa-gu, Seoul 05505, Korea Tel: +82-2-3010-3930, Fax: +82-2-3010-6701, E-mail: shwang@amc.seoul.kr

Copyright (C) 2019 by The Korean Association of Hepato-Biliary-Pancreatic Surgery

This is an Open Access article distributed under the terms of the Creative Commons Attribution Non-Commercial License (http://creativecommons.org/ licenses/by-nc/4.0) which permits unrestricted non-commercial use, distribution, and reproduction in any medium, provided the original work is properly cited. Annals of Hepato-Biliary-Pancreatic Surgery • pISSN: 2508-5778 - eISSN: 2508-5859 

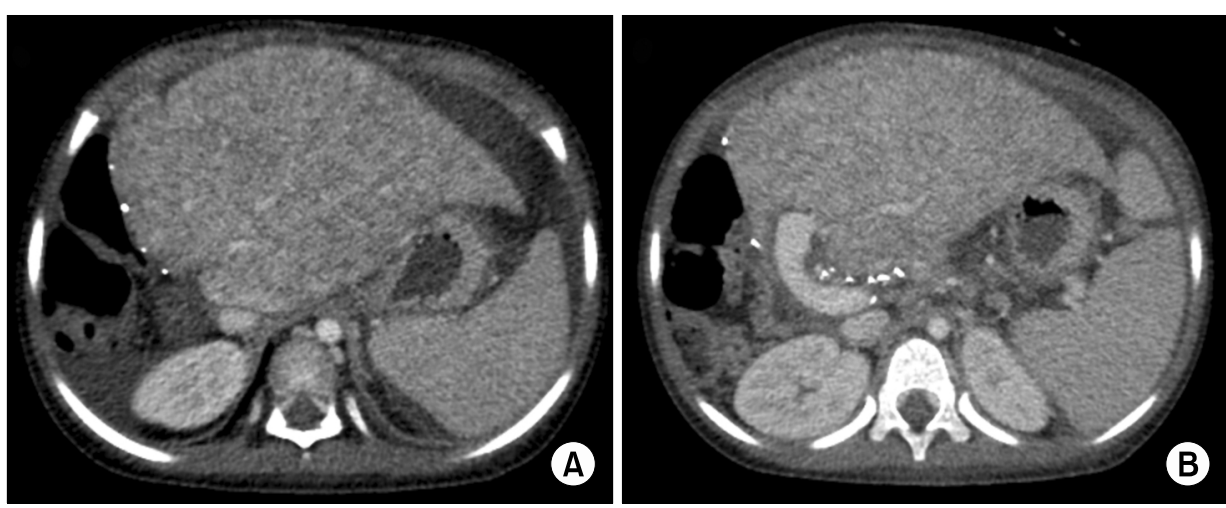

Fig. 1. Pretransplant computed tomography findings of the recipient. The first liver graft was severely damaged (A), but the interposed portal vein was well maintained (B).
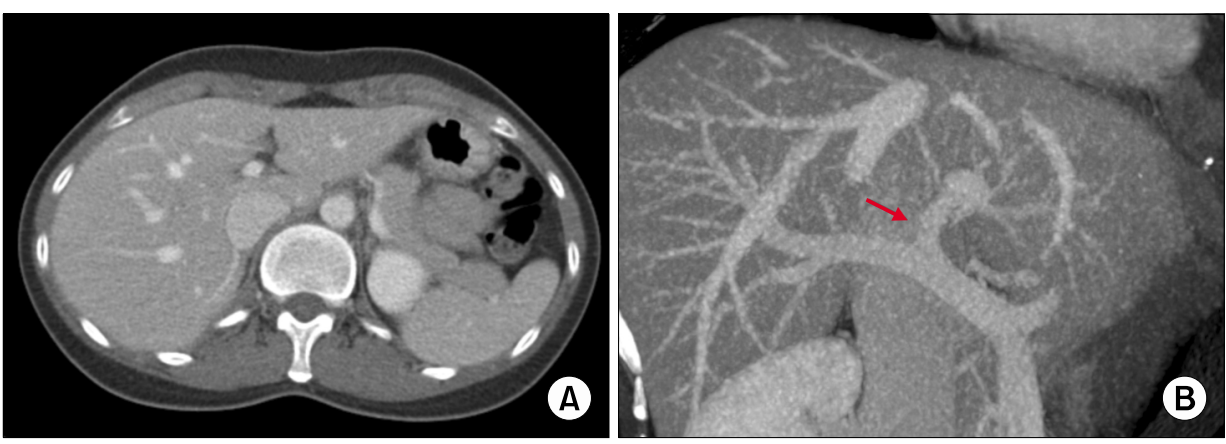

Fig. 2. Computed tomography findings of the donor. The left liver was small (A) and a waist is present at the first-order left portal vein (B, arrow).
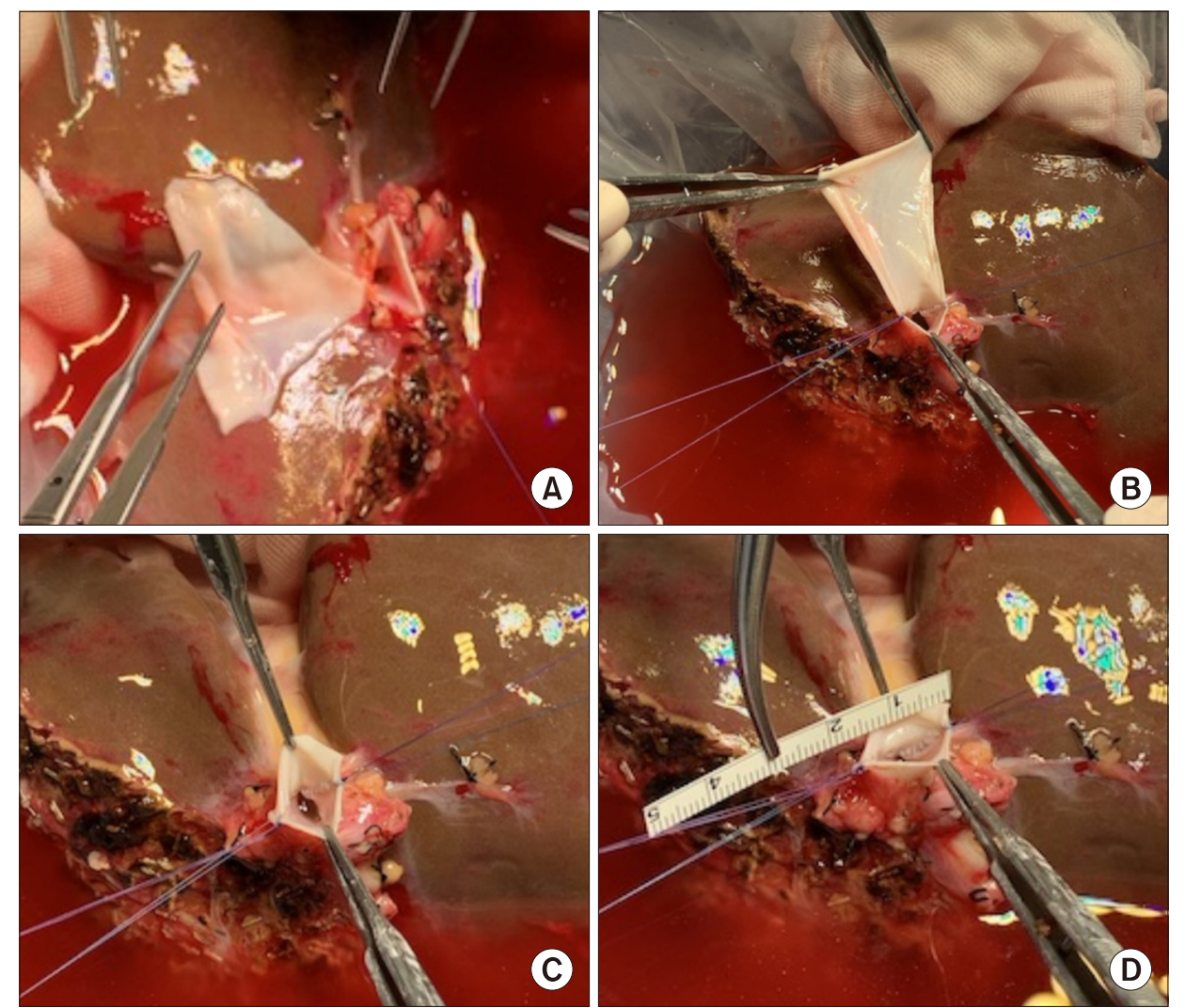

Fig. 3. Operative photographs of portal vein (PV) venoplasty. The ventral wall of the graft PV is incised and a large-sized patch is attached (A). A vein patch is anastomosed (B). The final shape of enlarged graft PV is visible $(\mathrm{C})$, and its diameter is more than $15 \mathrm{~mm}(\mathrm{D})$. cause the left PV was waisted at the first-order PV (Fig. 2).

In contrast, the diameter of the recipient PV was $12 \mathrm{~mm}$ because an iliac vein conduit was interposed to cope with portal hypoplasia at the first LDLT operation (Fig. 1). To resolve this graft PV waist-associated size mismatching, a longitudinal incision was made at the graft PV stump 

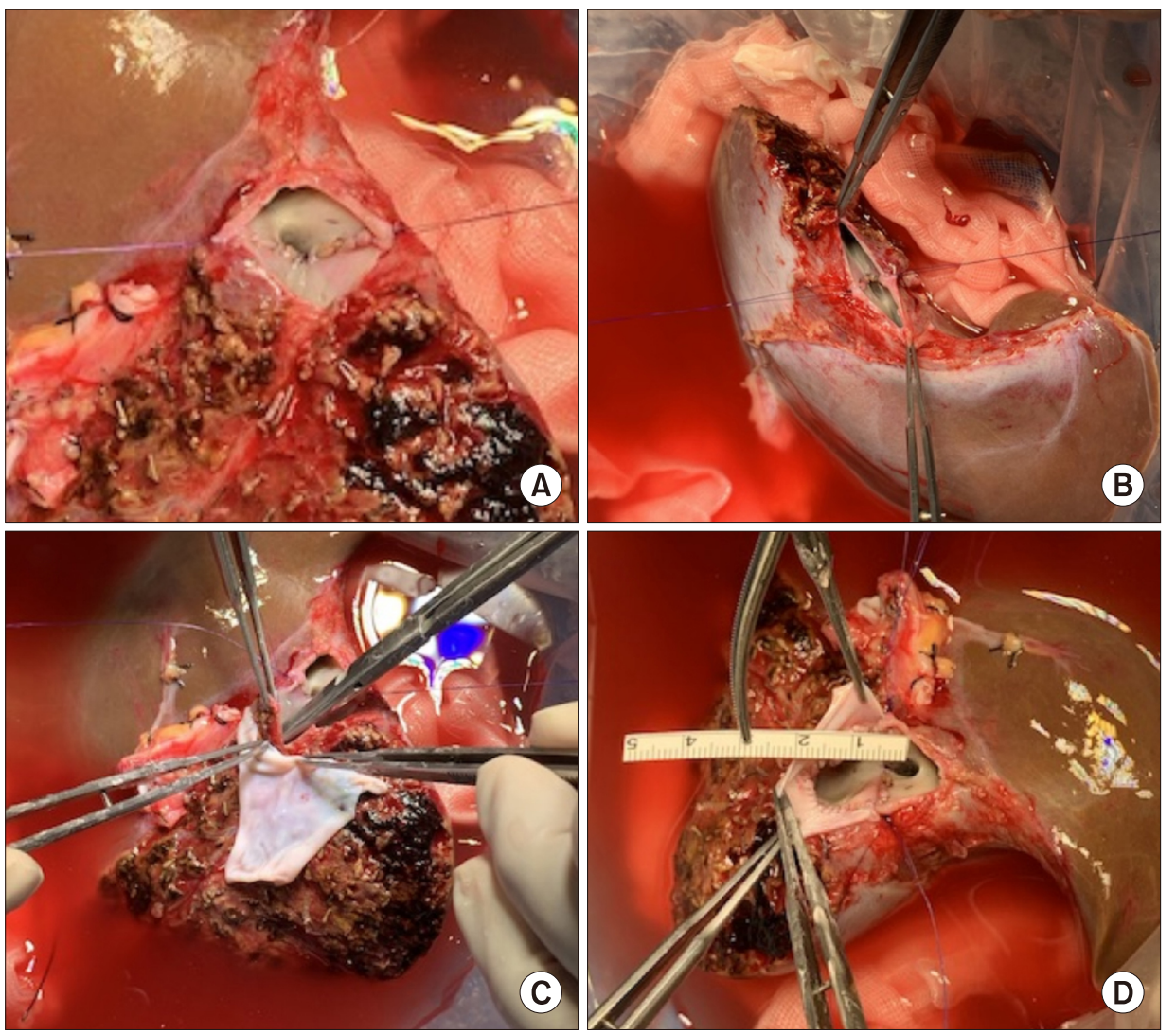

Fig. 4. Operative photographs of hepatic vein (HV) venoplasty. The middle and left HVs are unified (A and B). An incision is applied at the middle $\mathrm{HV}$ trunk and a vein patch is attached (C). The size of conjoined outflow orifice was measured to be approximately 30 $\mathrm{mm}$ (D).

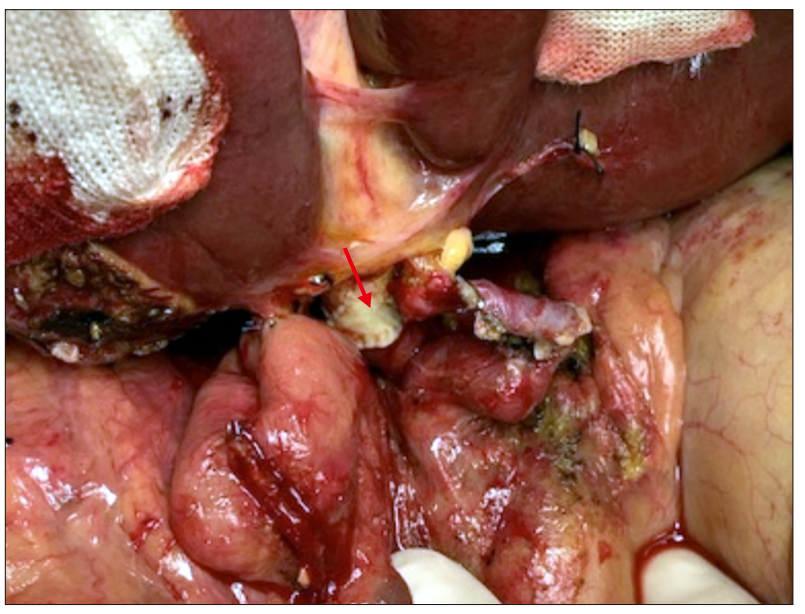

Fig. 5. Operative photograph taken after all reconstructions. An arrow indicates the vein patch at the portal vein anastomosis.

to release the waist. A small cold-preserved fresh iliac vein patch was attached to widen the graft PV orifice (Fig. 3). The size of patch was adjusted to match with the size of the recipient PV.

In addition to the PV venoplasty, the left and middle hepatic vein orifices were unified, and a vein patch was attached to the middle hepatic vein side to widen the con-

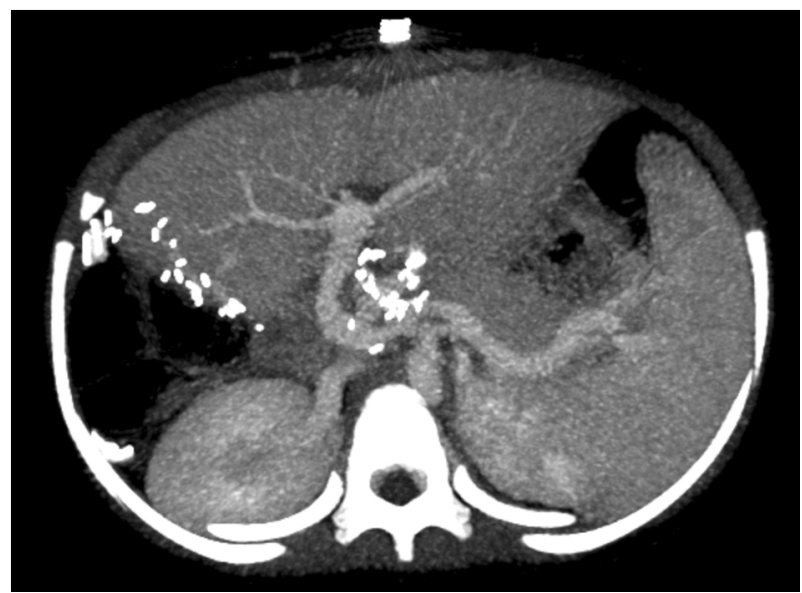

Fig. 6. Computed tomography finding of the recipient taken 2 weeks after transplantation. The reconstructed portal vein appears streamlined without noticeable stenosis.

joined outflow orifice according to our standardized LDLT procedures (Fig. 4).

Graft implantation was uneventful, along the orders of hepatic vein anastomosis under total occlusion of the inferior vena cava, end-to-end portal vein anastomosis, portal reperfusion, hepatic artery anastomosis under surgical microscopy and hepaticojejunostomy using the previously 
made jejunal limb (Fig. 5). For hepatic vein and PV reconstruction, we used continuous running sutures using 5-0 and 6-0 polydioxanone (PDS) respectively. We have do not applied interrupted sutures combined with continuous running sutures using polypropylene (Prolene).

The patient recovered uneventfully and is doing well to date for 6 months. The portal vein showed a streamlined configuration without anastomotic stenosis after the second LDLT operation (Fig. 6).

\section{DISCUSSION}

In pediatric LDLT, PV stenosis is one of the most common and most critical complications. Patients with biliary atresia have suffered from periportal inflammation and fibrosis due to recurrent cholangitis, by which the recipient PV becomes hypoplastic and sclerotic PV. ${ }^{3,4}$ To cope with such an intractable PV anatomy, we adopted an interposition graft for PV reconstruction. ${ }^{5}$ The favorable long-term result of PV interposition graft was shown at the time of retransplantation operation in this case.

In this case, graft PV was smaller than the recipient PV. Such size mismatching of PV is often encountered in adult LDLT because of aneurysmal dilatation of recipient PV. In most cases of adult LDLT using a right liver graft, direct anastomosis of PVs is often feasible despite presence of considerable size discrepancy. If the recipient $\mathrm{PV}$ is too large to perform direct anastomosis, a funneling fence can be attached to the graft PV for easy anastomosis. ${ }^{2}$ However, if the diameter of right liver graft PV is $<8 \mathrm{~mm}$, it can induce anastomotic stenosis even though a growth factor is fully given at the suture material. We have experienced a few cases of PV anastomotic stenosis so far due to small-sized graft PV in >5000 LDLT cases, but graft PV widening was not performed because graft $\mathrm{PV}$ is considered as being a no-touch area.

In donor liver anatomy of this case, the native left PV has a waist at its first-order level, which is an unusual finding. Since manipulation of the single graft PV is usually unnecessary, we have considered it as a no-touch area. Meanwhile, unification of two graft PV orifices is a standard procedure. ${ }^{6-10}$ In thinking out of the box, we performed wedged-patch venoplasty to exceptionally nar- row graft PV. The surgical technique for wedged-patch venoplasty is intuitive and simple because we accumulated similar experience on graft hepatic vein venoplasty, as shown in this case. ${ }^{11}$ The lesson learned from this case can be applied to adult LDLT cases which has an unusually small graft PV.

In conclusion, we believe that this wedged-patch venoplasty technique can be applied to small-sized graft PV to cope with PV size mismatching in LDLT.

\section{REFERENCES}

1. Kang SH, Hwang S, Jung DH, Ahn CS, Moon DB, Ha TY, et al. Unification venoplasty to cope with recipient portal vein anomaly during living donor liver transplantation. Transplant Proc 2013;45:3000-3004.

2. Moon DB, Lee SG, Ahn CS, Ha TY, Park GC, Yu YD. Side-to-end renoportal anastomosis using an externally stented polytetrafluoroethylene vascular graft for a patient with a phlebosclerotic portal vein and a large spontaneous splenorenal shunt. J Am Coll Surg 2011;212:e7-e11.

3. Chen CL, Concejero A, Wang CC, Wang SH, Lin CC, Liu YW, et al. Living donor liver transplantation for biliary atresia: a single-center experience with first 100 cases. Am J Transplant 2006;6:2672-2679.

4. Ou HY, Concejero AM, Huang TL, Chen TY, Tsang LL, Chen CL, et al. Portal vein thrombosis in biliary atresia patients after living donor liver transplantation. Surgery 2011;149:40-47.

5. Hwang S, Kim DY, Ahn CS, Moon DB, Kim KM, Park GC, et al. Computational simulation-based vessel interposition reconstruction technique for portal vein hypoplasia in pediatric liver transplantation. Transplant Proc 2013;45:255-258.

6. Kwon JH, Hwang S, Song GW, Moon DB, Park GC, Kim SH, et al. Conjoined unification venoplasty for triple portal vein branches of right liver graft: a case report and technical refinement. Korean J Hepatobiliary Pancreat Surg 2016;20:61-65.

7. Lee HJ, Hwang S, Ahn CS, Kim KH, Moon DB, Ha TY, et al. Long-term outcomes of portal Y-graft interposition for anomalous right portal veins in living donor liver transplantation. Transplant Proc 2012;44:454-456.

8. Hwang S, Lee SG, Ahn CS, Kim KH, Moon DB, Ha TY, et al. Technique and outcome of autologous portal Y-graft interposition for anomalous right portal veins in living donor liver transplantation. Liver Transpl 2009;15:427-434.

9. Lee SG, Hwang S, Kim KH, Ahn CS, Park KM, Lee YJ, et al. Approach to anatomic variations of the graft portal vein in right lobe living-donor liver transplantation. Transplantation 2003;75(3 Suppl):S28-S32.

10. Ha TY, Hwang S, Moon DB, Ahn CS, Kim KH, Song GW, et al. Conjoined unification venoplasty for graft double portal vein branches as a modification of autologous Y-graft interposition. Liver Transpl 2015;21:707-710.

11. Hwang S, Kim KH, Kim DY, Kim KM, Ahn CS, Moon DB, et al. Anomalous hepatic vein anatomy of left lateral section grafts and customized unification venoplasty for pediatric living donor liver transplantation. Liver Transpl 2013;19:184-190. 